\title{
Recent clinical trials support continued emphasis on patient-first over modality-first approaches to initial test selection in patients with stable ischemic heart disease
}

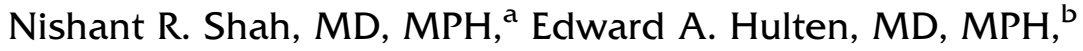 \\ Suman Tandon, MD, ${ }^{\mathrm{c}}$ Venkatesh L. Murthy, MD, PhD, ${ }^{\mathrm{d}}$ Sharmila Dorbala, MD, \\ $\mathrm{MPH},{ }^{\mathrm{e}}$ and Randall C. Thompson, $\mathrm{MD}^{\mathrm{f}}$ \\ a Division of Cardiology, Department of Medicine, Brown University Alpert Medical School, \\ Providence, RI \\ b Department of Medicine, F. Edward Hebert Medical School Uniformed Services, University of \\ Health Sciences, Bethesda, MD \\ c Department of Medicine, New York University School of Medicine, New York, NY \\ d Departments of Medicine and Radiology, University of Michigan Medical School, Ann Arbor, \\ MI \\ e Departments of Medicine and Radiology, Harvard Medical School, Boston, MA \\ f Department of Medicine, University of Missouri-Kansas City School of Medicine, Kansas City, \\ KS
}

Received Dec 20, 2021; accepted Dec 20, 2021

doi: 10.1007/s12350-022-02908-7

Current guidelines ${ }^{1,2}$ and appropriate use criteria ${ }^{3}$ used by clinicians in the USA and in Europe acknowledge the central role of cardiovascular imaging in contemporary diagnosis and management of patients with stable ischemic heart disease (SIHD). These documents recommend a tailored, patient-centered approach in selecting exercise electrocardiography (EE), stress echocardiography (SE), stress single-photon emission computed tomography (SPECT) myocardial perfusion imaging (MPI), stress positron emission tomography (PET) MPI, coronary CT angiography (CCTA), stress cardiac magnetic resonance (CMR) imaging, or invasive coronary angiography (ICA) as the initial diagnostic test in patients with SIHD. Furthermore, as illustrated in Figure 1, these documents emphasize shared decisionmaking between clinicians and patients that incorporates patient characteristics, test characteristics, and the

Reprint requests: Nishant R. Shah, MD, MPH, Division of Cardiology, Department of Medicine, Brown University Alpert Medical School, 830 Chalkstone Avenue, Providence, RI 02908; nishmd@gmail.com J Nucl Cardiol $1071-3581 / \$ 34.00$

Copyright $\odot 2022$ The Author(s) under exclusive licence to American Society of Nuclear Cardiology clinical presentation to ensure performance of 'the right test for the right patient at the right time.'

Over the past several years, a number of randomized clinical trials evaluating various testing strategies in patients with SIHD have been published, the most notable of which are SCOT-HEART ${ }^{4}$, PROMISE $^{5}$, and ISCHEMIA $^{6}$. The results of these landmark trials have recently been used by some to advocate for a 'CCTAfirst' algorithm that emphasizes CCTA as the default initial test in nearly all patients with SIHD. ${ }^{7,8,9}$ In this editorial, we show how these trials support CCTA as a first-line option, but also affirm the clinical value of functional-first testing in patients with SIHD.

\section{SCOT-HEART}

The SCOT-HEART trial ${ }^{4}$ is often cited to validate 'CCTA-first' testing algorithms in patients with SIHD. However, this is not consistent with the trial design ${ }^{10}$ or its results. Among the 4146 patients in this United Kingdom trial, $85 \%$ of the patients in the trial underwent EE and nearly a third underwent 'further investigations' that included radionuclide stress imaging or ICA before randomization to CCTA. Moreover, it is unclear how pre-randomization testing might have impacted the decision-making of the 2613 eligible patients who 


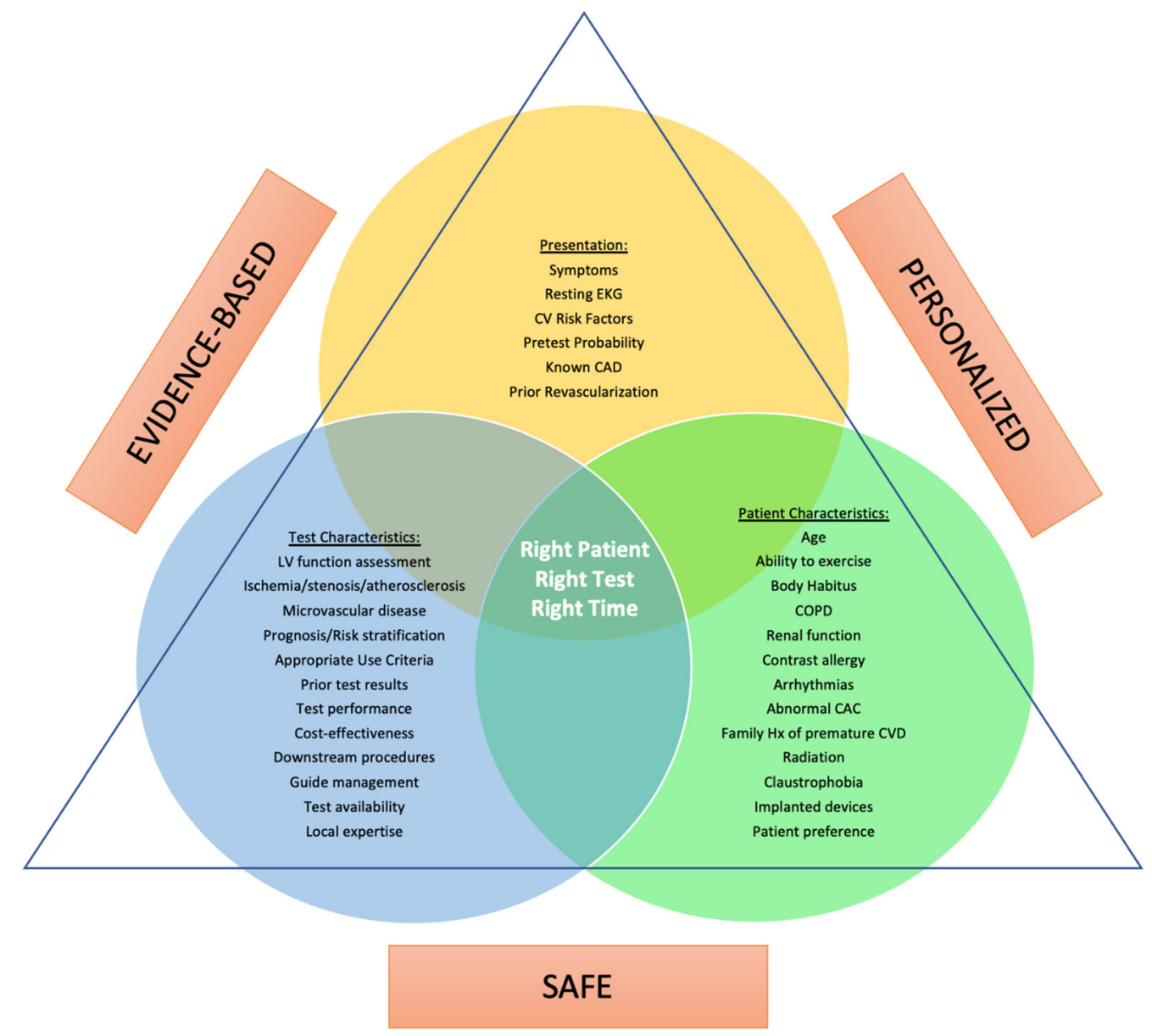

Figure 1. Selection of initial testing in patients with SIHD should be evidence based, personalized, and safe. A multitude of factors, including patient characteristics, the clinical presentation, and test characteristics, must all be appropriately weighed to achieve the ideal of performing the right test for the right patient at the right time.

declined participation in the trial and the 547 clinicians who declined participation on behalf of their patients. As such, the SCOT-HEART cohort may not be truly representative of all patients with SIHD and it is unclear how applicable the study results are for healthcare systems outside of the United Kingdom. Moreover, it is critically important to understand that SCOT-HEART largely studied a 'CCTA-second' testing algorithm. This belies the argument, often used by CCTA-first advocates, that anatomic findings on CCTA alone drove increased utilization of preventive therapies and the significant reduction in non-fatal myocardial infarction (MI) observed at 5 years in the CCTA arm of SCOTHEART. ${ }^{11}$ In reality, the anatomic findings on CCTA were interpreted and acted upon in the context of already obtained functional testing. In addition, rates of ICA were higher in the CCTA arm than in the usual care arm in the early follow-up period of SCOT-HEART, a finding that is consistent with prior studies and metaanalyses. $^{12,13}$ It is possible that early ICA with or without revascularization - not only the previous CCTA - drove earlier utilization of preventive therapies and positive behavioral changes that in turn reduced the risk of non-fatal MI over the duration of the follow-up period. Even if we are willing to ascribe these changes solely to performance of CCTA, the cardiovascular risk threshold for initiation of preventive therapies has been lowered ${ }^{14}$ since SCOT-HEART was completed. As such, it is unclear if the benefit ascribed to CCTA could be replicated again today. Taking all of the above together, we do not believe the SCOT-HEART data should be used to advocate for a default CCTA-first testing algorithm in patients with SIHD. 


\section{PROMISE}

In contrast to SCOT-HEART, the PROMISE trial ${ }^{5}$ was a head-to-head trial of CCTA-first versus 'functional-first' testing (i.e., EE, SPECT MPI, PET MPI, or SE) in patients with SIHD. In PROMISE, CCTA-first was equivalent to functional-first testing with respect to the primary study outcome (all-cause death, non-fatal MI, hospitalization for unstable angina, or major procedural complication) over 2-year follow-up. The recently published RESCUE trial ${ }^{15}$ also showed no difference in the primary study outcome (cardiac death, myocardial infarction, or revascularization) in patients with SIHD who underwent CCTA compared to those who underwent SPECT MPI as the first imaging test. These two trials suggest that CCTA may have a role as a first-line testing option to evaluate patients with SIHD with characteristics similar to the subjects studied. However, they do not in any way support that CCTA should be the single default test of choice in patients with SIHD as CCTA-first advocates have recommended.

A post hoc analysis of PROMISE showed that a CCTA-first algorithm may result in lower risk of cardiovascular death or MI compared to a functionalfirst strategy in the subgroup of patients with diabetes and SIHD. ${ }^{16}$ In general, post hoc analyses of clinical trials are only hypothesis-generating and should not be used as the basis of changes in health policy. Second, in this particular analysis, patients with diabetes who underwent CCTA had a lower cardiovascular event rate than patients without diabetes who underwent CCTA, strongly suggesting the play of chance and possibly collider stratification (i.e., high-risk diabetes patients were not randomized). Lastly with regard to this analysis, it has the same major limitation as mentioned above for SCOT-HEART - patients in the CCTA-first arm were more likely to undergo early ICA, again raising the possibility that ICA with or without revascularization could have contributed to early utilization of preventive therapies and positive behavioral changes that in turn reduced the subsequent risk of cardiovascular death or MI.

A separate post hoc analysis of PROMISE showed that CCTA, by identifying patients with non-obstructive epicardial CAD, provides better prognostic information than functional testing in patients with SIHD. ${ }^{17}$ Indeed, an accumulating body of evidence strongly suggests that total atherosclerotic plaque burden in the epicardial coronary arteries on CCTA may have better prognostic value for adverse cardiovascular events than assessment of stenosis alone. However, data from SCOT-HEART ${ }^{18}$ and national clinical registries ${ }^{19}$ suggest this risk may be adequately captured with simple non-contrast CAC scoring without the need for a full contrast-enhanced
CCTA to quantify non-calcified plaque. Additionally, in PROMISE classification of stress MPI studies as normal, mildly abnormal, moderately abnormal, and severely abnormal was solely based on EE abnormalities and relative left ventricular (LV) perfusion findings, such as inducible myocardial ischemia, myocardial scar, and transient ischemic dilation. Non-perfusion findings associated with elevated cardiovascular risk (i.e., LV dilatation with reduced LV ejection fraction, increased right ventricular radionuclide uptake) were not included. Nor was PET MPI-derived myocardial blood flow (MBF) quantification, which can identify vasomotor dysfunction and microvascular angina ${ }^{20}$ and has been shown to improve the prognostic value of PET MPI in numerous patient populations. ${ }^{21,22,23,24,25,26}$ Also not included were CAC scores or visually estimated CAC scores (VECAC) obtained from CT images, now often obtained for attenuation correction in the performance of SPECT and PET MPI and known to improve prognostic value over perfusion interpretation alone. ${ }^{27,28,29,30,31}$ As such, PROMISE was not designed to comprehensively compare the prognostic value nor the cost effectiveness $^{32,33}$ of CCTA versus functional testing, and in some respects may already be outdated given improvements in both MPI and CCTA technologies.

Lastly, CCTA-first advocates often fail to mention key analyses from PROMISE that highlight some of the real-world challenges associated with performance of CCTA. For example, the original clinical CCTA interpretations in PROMISE had fairly poor specificity given that core lab interpretation resulted in $41 \%$ fewer patients being reported as having significant $\mathrm{CAD} .{ }^{34}$ Furthermore, incidental findings were much more frequently identified in the CCTA arm (11.6\%) than in the functional testing arm (0.7\%) in PROMISE. ${ }^{35}$ Most commonly, these incidental findings were pulmonary nodules that often generated downstream costs associated with additional imaging and clinical visits. More recently, RESCUE showed the same finding; $32.8 \%$ patients in the CCTA arm had incidental findings (59 of whom required follow-up imaging), while only $1.7 \%$ of patients in the SPECT MPI arm had incidental findings ( 2 of whom required follow-up imaging). ${ }^{15}$ Curiously, this significant cost differential between CCTA and SPECT MPI was not factored into a cost-effectiveness analysis performed by the United Kingdom National Institute for Health and Care Excellences (NICE) ${ }^{36}$, nor into a more recent cost-effectiveness analysis developed from PROMISE data. ${ }^{32}$ To be fair, there are data suggesting relatively poor specificity of clinical SPECT MPI interpretations as well. In ISCHEMIA, $14.2 \%$ of the patients who were randomized on the basis of sitedetermined moderate or severe ischemia on stress imaging had only mild or no ischemia on subsequent 
core lab interpretation. ${ }^{37}$ Clearly neither CCTA nor SPECT MPI is a 'perfect' test in this respect, but that is precisely our point; the available data simply don't support superiority of any modality-first testing algorithm in patients with SIHD. Overall, we believe PROMISE and its associated post hoc analyses suggest a possible role for CCTA as a first-line option in appropriately selected patients with SIHD, but nothing more than that.

\section{ISCHEMIA}

Last but not least, the ISCHEMIA trial ${ }^{5}$ was not a head-to-head trial of initial CCTA versus functional testing, like PROMISE or RESCUE. Instead, ISCHEMIA was designed to study whether an initial invasive strategy, as compared to optimal medical therapy alone, reduced the risk of ischemic events or all-cause death in patients with SIHD and at least moderate ischemia on functional testing (EE, SPECT MPI, or PET MPI). Put more simply, ISCHEMIA was designed to test different therapeutic strategies, not different diagnostic testing strategies. Furthermore, the trial was designed ${ }^{38}$ simi- $^{-}$ larly to SCOT-HEART in that CCTA was conducted after functional testing (49.6\% SPECT or PET MPI, $24.5 \%$ EE, $20.9 \%$ SE, 5\% stress CMR) had already been performed (i.e., 'CCTA-second'). However, the blinded CCTA had a limited role to exclude enrolled patients with significant unprotected left main coronary artery stenosis and those without obstructive CAD in other epicardial coronary arteries. The first results from ISCHEMIA, after 3 years of follow-up showed that event rates were low in both randomization arms and that an initial invasive strategy did not improve outcomes compared to optimal medical therapy alone. ${ }^{5}$ CCTA-first advocates often contrast this result with that of SCOT-HEART to argue that CCTA is superior to functional testing with respect to its ability to positively impact downstream clinical management and outcomes. However, only 970 of the 5179 randomized patients (18.7\%) had $\geq 15 \%$ ischemia on SPECT MPI, a previously proposed cutoff for overall mortality benefit from revascularization established by prior long-term observational studies. ${ }^{39}$ Additionally, there is evidence that the benefits of revascularization were underestimated in ISCHEMIA because of the selective nature of the study population. ${ }^{40}$ Lastly, a more recent prespecified and nuanced analysis of ISCHEMIA including longer follow-up showed that spontaneous type 1 MIs (distinguished from procedure-related MIs) were more frequent in the optimal medical therapy arm and were associated with subsequent cardiovascular death. ${ }^{41}$ Together, we believe the data from ISCHEMIA do not support moving to a default CCTA-first algorithm.

\section{SUMMARY}

SCOT-HEART, PROMISE, and ISCHEMIA are landmark trials that importantly helped establish CCTA as an appropriate initial test in select patients with SIHD. However, we do not believe the data from these trials provide a strong scientific rationale to move to a default CCTA-first algorithm in the USA. We thus strongly encourage future writing groups updating guidelines and appropriate use criteria for the diagnosis and management of patients with SIHD not to use common misinterpretations of these trials in adopting a default CCTA-first algorithm - or any other default modalityfirst algorithm. Instead, they should aim to apply scientific, evidence-based, patient-centered approaches that focus on performing the right test for the right patient at the right time.

\section{Declarations}

\section{Disclosure}

The authors have no relevant disclosures. The views expressed here are those of the authors only and are not to be construed as those of the United States Army, the Department of the Defense, the Defense Health Agency, or the United States Government. The identification of specific products or scientific instrumentation is considered an integral part of the scientific endeavor and does not constitute endorsement or implied endorsement on the part of the author(s), the Department of Defense, or any component agency.

\section{References}

1. Fihn SD, Blankenship JC, Alexander KP, Bittl JA, Byrne JG, Fletcher BJ, et al. 2014 ACC/AHA/AATS/PCNA/SCAI/STS focused update of the guideline for the diagnosis and management of patients with stable ischemic heart disease: A report of the American College of Cardiology/American Heart Association Task Force on Practice Guidelines, and the American Association for Thoracic Surgery, Preventive Cardiovascular Nurses Association, Society for Cardiovascular Angiography and Interventions, and Society of Thoracic Surgeons. J Am Coll Cardiol 2014;64:1929-49.

2. Knuuti J, Wijns W, Saraste A, Capodanno D, Barbato E, FunckBrentano C, et al. 2019 ESC Guidelines for the diagnosis and management of chronic coronary syndromes: The Task Force for the diagnosis and management of chronic coronary syndromes of the European Society of Cardiology (ESC). Eur Heart J 2019;41:407-77.

3. Wolk MJ, Bailey SR, Doherty JU, Douglas PS, Hendel RC, Kramer CM, et al. ACCF/AHA/ASE/ASNC/HFSA/HRS/SCAI/ SCCT/SCMR/STS 2013 multimodality appropriate use criteria for the detection and risk assessment of stable ischemic heart disease: A report of the American College of Cardiology Foundation Appropriate Use Criteria Task Force, American Heart Association, American Society of Echocardiography, American Society of Nuclear Cardiology, Heart Failure Society of America, Heart 
Rhythm Society, Society for Cardiovascular Angiography and Interventions, Society of Cardiovascular Computed Tomography, Society for Cardiovascular Magnetic Resonance, and Society of Thoracic Surgeons. J Am Coll Cardiol 2013;2014:380-406.

4. The SCOT-HEART investigators. CT coronary angiography in patients with suspected angina due to coronary heart disease (SCOT-HEART): An open-label, parallel-group, multicentre trial. The Lancet 2015;385:2383-91.

5. Douglas PS, Hoffmann U, Patel MR, Mark DB, Al-Khalidi HR, Cavanaugh B, et al. Outcomes of anatomical versus functional testing for coronary artery disease. N Engl J Med 2015;372:1291300.

6. Maron DJ, Hochman JS, Reynolds HR, Bangalore S, O'Brien SM, Boden WE, et al. Initial invasive or conservative strategy for stable coronary disease. N Engl J Med 2020;382:1395-407.

7. Poon M, Lesser JR, Biga C, Blankstein R, Kramer CM, Min JK, et al. Current evidence and recommendations for coronary CTA first in evaluation of stable coronary artery disease. J Am Coll Cardiol 2020;76:1358-62.

8. Moss AJ, Williams MC, Newby DE, Nicol ED. The updated NICE guidelines: Cardiac CT as the first-line test for coronary artery disease. Curr Cardiovasc Imaging Rep. 2017;10:15.

9. Michos ED, Greenland P. Coronary computed tomography angiography in stable chest pain to prevent myocardial infarction and reduce costs-seeing is believing. JAMA Netw Open 2020;3:e2030996.

10. Newby DE, Williams MC, Flapan AD, Forbes JF, Hargreaves AD, Leslie SJ, et al. Role of multidetector computed tomography in the diagnosis and management of patients attending the rapid access chest pain clinic, The Scottish computed tomography of the heart (SCOT-HEART) trial: Study protocol for randomized controlled trial. Trials 2012;13:184.

11. SCOT-HEART Investigators, Newby DE, Adamson PD, Berry C, Boon NA, Dweck MR, et al. Coronary CT angiography and 5-year risk of myocardial infarction. N Engl J Med 2018;379:924-33.

12. Shreibati JB, Baker LC, Hlatky MA. Association of coronary CT angiography or stress testing with subsequent utilization and spending among Medicare beneficiaries. JAMA 2011;306:212836.

13. Bittencourt MS, Hulten EA, Murthy VL, Cheezum M, Rochitte CE, Di Carli MF, et al. Clinical outcomes after evaluation of stable chest pain by coronary computed tomographic angiography versus usual care a meta-analysis. Circulation 2016;9:e004419.

14. Grundy SM, Stone NJ, Bailey AL, Beam C, Birtcher KK, Blumenthal RS, et al. 2018 AHA/ACC/AACVPR/AAPA/ABC/ ACPM/ADA/AGS/APhA/ASPC/NLA/PCNA guideline on the management of blood cholesterol: A Report of the American College of Cardiology/American Heart Association Task Force on Clinical Practice Guidelines. Circulation 2019;139:e1082-143.

15. Stillman AE, Gatsonis C, Lima JAC, Liu T, Snyder BS, Cormack $\mathrm{J}$, et al. Coronary computed tomography angiography compared with single photon emission computed tomography myocardial perfusion imaging as a guide to optimal medical therapy in patients presenting with stable angina: The RESCUE trial. $J$ Am Heart Assoc. 2020;9:e017993.

16. Sharma A, Coles A, Sekaran NK, Pagidipati NJ, Lu MT, Mark $\mathrm{DB}$, et al. Stress testing versus $\mathrm{CT}$ angiography in patients with diabetes and suspected coronary artery disease. J Am Coll Cardiol 2019;73:893-902.

17. Hoffmann U, Ferencik M, Udelson JE, Picard MH, Truong QA, Patel MR, et al. Prognostic value of noninvasive cardiovascular testing in patients with stable chest pain: Insights from the PROMISE trial (prospective multicenter imaging study for evaluation of chest pain). Circulation 2017;135:2320-32.
18. Williams MC, Moss AJ, Dweck M, Adamson PD, Alam S, Hunter A, et al. Coronary artery plaque characteristics associated with adverse outcomes in the SCOT-HEART Study. J Am Coll Cardiol 2019;73:291-301.

19. Mortensen MB, Dzaye O, Steffensen FH, Botker HE, Jensen JM, Ronnow Sand NP, et al. Impact of plaque burden versus stenosis on ischemic events in patients with coronary atherosclerosis. J Am Coll Cardiol 2020;76:2803-13.

20. Gould KL, Johnson NP, Bateman TM, Beanlands RS, Bengel FM, Bober R, et al. Anatomic versus physiologic assessment of coronary artery disease. Role of coronary flow reserve, fractional flow reserve, and positron emission tomography imaging in revascularization decision-making. J Am Coll Cardiol 2013;62:1639-53.

21. Murthy VL, Naya M, Foster CR, Hainer J, Gaber M, Di Carli G, et al. Improved cardiac risk assessment with noninvasive measures of coronary flow reserve. Circulation 2011;124:2215-24.

22. Murthy VL, Naya M, Foster CR, Gaber M, Hainer J, Klein J, et al. Association between coronary vascular dysfunction and cardiac mortality in patients with and without diabetes mellitus. Circulation 2012;126:1858-68.

23. Taqueti VR, Shaw LJ, Cook NR, Murthy VL, Shah NR, Foster $\mathrm{CR}$, et al. Excess cardiovascular risk in women relative to men referred for coronary angiography is associated with severely impaired coronary flow reserve, not obstructive disease. Circulation 2017;135:566-77.

24. Shah NR, Charytan DM, Murthy VL, Skali Lami H, Veeranna V, Cheezum MK, et al. Prognostic value of coronary flow reserve in patients with dialysis-dependent ESRD. J Am Soc Nephrol 2016;27:1823-9.

25. Patel KK, Spertus JA, Chan PS, Sperry BW, Al Badarin F, Kennedy KF, et al. Myocardial blood flow reserve assessed by positron emission tomography myocardial perfusion imaging identifies patients with a survival benefit from early revascularization. Eur Heart J 2020;41:759-68.

26. Bateman TM, Heller GV, Beanlands R, Calnon DA, Case J, deKemp R, et al. Practical guide for interpreting and reporting cardiac PET measurements of myocardial blood flow: An Information Statement from the American Society of Nuclear Cardiology, and the Society of Nuclear Medicine and Molecular Imaging. J Nucl Cardiol 2021;28:768-87.

27. Rozanski A, Berman DS. The synergistic use of coronary artery calcium imaging and noninvasive myocardial perfusion imaging for detecting subclinical atherosclerosis and myocardial ischemia. Curr Cardiol Rep 2018;20:59.

28. Chang SM, Nabi F, Xu J, Peterson LE, Achari A, Pratt CM, et al. The coronary artery calcium score and stress myocardial perfusion imaging provide independent and complementary prediction of cardiac risk. J Am Coll Cardiol 2009;54:1872-82.

29. Einstein AJ, Johnson LL, Bokhari S, Son J, Thompson RC, Bateman TM, et al. Agreement of visual estimation of coronary artery calcium from low-dose $\mathrm{CT}$ attenuation correction scans in hybrid PET/CT and SPECT/CT with standard Agatston score. J Am Coll Cardiol 2010;56:1914-21.

30. Le VT, Knight S, Min DB, McCubrey RO, Horne BD, Jensen KR, et al. Absence of coronary artery calcium during positron emission tomography stress testing in patients without known coronary artery disease identifies individuals with very low risk of cardiac events. Circ Cardiovasc Imaging 2020;13:e009907.

31. Trpkov C, Savtchenko A, Liang Z, Feng P, Southern DA, Wilton $\mathrm{SB}$, et al. Visually estimated coronary artery calcium score improves SPECT-MPI risk stratification. Int J Cardiol Heart Vasc 2021;35:100827.

32. Karady J, Mayrhofer T, Ivanov A, Foldyna B, Lu MT, Ferencik M, et al. Cost-effectiveness analysis of anatomic vs functional index 
testing in patients with low-risk stable chest pain. JAMA Netw Open 2020;3:e2028312.

33. Mark DB, Douglas PS, Daniels MR. Economic outcomes with anatomical versus functional diagnostic testing for coronary artery disease. Ann Intern Med 2016;165:891.

34. Lu MT, Meyersohn NM, Mayrhofer T, Bittner DO, Emami H, Puchner SB, et al. Central core laboratory versus site interpretation of coronary CT angiography: Agreement and association with cardiovascular events in the PROMISE trial. Radiology 2018;287:87-95.

35. Lu MT, Douglas PS, Udelson JE, Adami E, Ghoshhajra BB, Picard $\mathrm{MH}$, et al. Safety of coronary CT angiography and functional testing for stable chest pain in the PROMISE trial: A randomized comparison of test complications, incidental findings, and radiation dose. J Cardiovasc Comput Tomogr 2017;11:373-82.

36. Skinner JS, Smeeth L, Kendall JM, Adams PC, Timmis A and Chest Pain Guideline Development G. NICE guidance. Chest pain of recent onset: assessment and diagnosis of recent onset chest pain or discomfort of suspected cardiac origin. Heart. 2010;96:974-8.

37. Gibbons RJ. Myocardial ischemia in the management of chronic coronary artery disease: past and present. Circ Cardiovasc Imaging. 2021:CIRCIMAGING120011615.
38. Group ITR, Maron DJ, Hochman JS, O'Brien SM, Reynolds HR, Boden WE, et al. International study of comparative health effectiveness with medical and invasive approaches (ISCHEMIA) trial: Rationale and design. Am Heart J 2018;201:124-35.

39. Hachamovitch R, Rozanski A, Shaw LJ, Stone GW, Thomson LE, Friedman JD, et al. Impact of ischaemia and scar on the therapeutic benefit derived from myocardial revascularization vs. medical therapy among patients undergoing stress-rest myocardial perfusion scintigraphy. Eur Heart J 2011;32:1012-24.

40. Al-Mallah MH, Ahmed AI, Nabi F, Chang SM, Kleiman NS, Chamsi-Pasha MA, et al. Outcomes of patients with moderate-tosevere Ischemia excluded from the ischemia trial. J Nucl Cardiol 2021. https://doi.org/10.1007/s12350-021-02679-7

41. Chaitman BR, Alexander KP, Cyr DD, Berger JS, Reynolds HR, Bangalore S, et al. Myocardial infarction in the ISCHEMIA trial: Impact of different definitions on incidence, prognosis, and treatment comparisons. Circulation. 2021;143:790-804.

Publisher's Note Springer Nature remains neutral with regard to jurisdictional claims in published maps and institutional affiliations. 